\title{
Epidemiological and Clinical Aspects of Ulcerative Colitis in Mosul city, Iraq
}

\author{
Muhammed Babakir-Mina \\ Medical Laboratory Department \\ Technical College of Health \\ Sulaimani Polytechnic University \\ Sulaimani, Iraq \\ m.babakir@yahoo.com
}

Volume 4 - Special Issue: 3rd International Conference on Health \& Medical Sciences: Insight into Advanced Medical Research (ICHMS 2019)

DOI:

10.24017/science.2019

ICHMS.6

Received: 22 May 2019

Accepted:

28 June 2019
Abstract

Ulcerative Colitis (UC) is a chronic inflammatory disorder of the gastrointestinal tract with heterogeneous disease presentation. A cross-sectional descriptive study was undertaken in Mosul General Hospital. The study was conducted using two distinct methodologies. An observational checklist was used by the researcher to assess the patients' characteristics and factors related to UC from 200 hospitalized patients from December 2018 to April 2019. Data were entered into spreadsheets and analyzed in Statistical Package for Social Sciences (SPSS) version 22. The results showed that $49.0 \%$ of patients was males and $51.0 \%$ was female; the mean age was 46.36 years old. Elderly stage ( $>45$ years of age) makes the highest proportion of the patients 99 (49.5\%). The majority of patients was from urban or inside Mosul city center 140 (70\%). The study also showed that the more frequency of patients 103 (51.5\%) were in severe condition. Patients were used or given more antibiotics, they will be liked to get UC 191 (95.5\%) and the relation was found to be statistically significant at $(p<0.001)$. The study showed that $95(47.5 \%)$ of all cases had a previous family history of UC. Out of 102 female patients, 45 (44.1\%) were more frequently under uses of contraceptive pills. 60 (58.8\%) of patients was in severe cases of UC and followed by moderate 35 (34.3\%). Out of 103 severe cases, 60 of them were female. These differences were statistically significant at $(p<0.05)$. In addition, out of 45 female patients were used oral contraceptive pills, 30 (66.7\%) of them were in severe cases of UC and followed by 14 (31.1\%) were in moderate cases. Majority of patients previously were sensitive to spices 160 (80.0\%) and followed by fish and eggs 21 (10.5) 16 (8.0\%) respectively. In addition, out of 160 spices sensitive patients, 80 (50.5\%) of them were in severe cases and 61 (38.1\%) were in moderate cases. Statistically, these differences are significant at $(p<0.05)$.

In the conclusion, UC among late adult in our community needs critical care and monitoring. The female patients were at risk of UC especially, who uses oral contraceptive pills. The random and more antibiotic uses are considered as major risk factors lead to cause UC.

Keywords: Ulcerative colitis, Mosul city, Oral contraceptive pills, Food sensitivity. 


\section{INTRODUCTION}

Ulcerative colitis (UC) is an infection of the large intestine (colon). It has irritating and swelling of colon symptoms, which causes inflammation and then leading to cause ulcers in the lining of colon [1]. It is considered as a type of inflammatory bowel diseases, but it can be differentiated from Crohn's disease (CD) and irritable bowel syndrome (IBS) which have similar symptoms to UC [2].

The one of the main symptoms of UC is bloody diarrhea. Other problems include crampy belly pain, not feeling hungry, weight loss, weakness, anemia, and fever. For example, CD causes inflammation the digestive tract. UC only affects the lining site of colon. Furthermore, IBS has some similar symptoms with UC, however, it cannot able to cause ulcers, it has an issue with the intestinal muscles [3]. Proctitis is inflammation of the rectum. Left-sided colitis is involvement of the descending colon, which runs along the patient's left side, up to the splenic flexure and the beginning of the transverse colon. Extensive colitis is inflammation extending beyond the reach of enemas. Pancolitis involves the inflammation of the entire colon, extending from the rectum to the cecum, beyond which the small intestine begins [4]. In addition to the extent of involvement, people may also be characterized by the severity of their disease: Mild, moderate and severe [4]. In spite of unknown causes UC is unknown; however, there are several factors such as disorder of immune system, genetics, abnormality of bacterial flora in the gut, and environmental factors are usually having a relation with UC [5-9].

This study aims to investigate the epidemiological and clinic aspects of ulcerative colitis in Mosul city, Iraq.

\section{LITERATURE REVIEW}

Globally, the geographic distribution of UC has the highest incidence rate in Canada, New Zealand and the UK [10,11]. The first peak of UC occurs between $(15-25)$ years-old $[12,13,14]$. Globally, UC has variance in demographic and clinical characteristics. Phenotypic heterogeneity of UC might be related to environmental and genetic factors [15]. For instance, the investigations have revealed that UC evolution is usually less severe in Asian countries in comparison with developed western countries [16,17].

According to study in west of Iran, out of the 150 diagnosed patients with UC, 84 (56\%) was women and 66 (44 \%) was men and male to female ratio equal to 1.27 . The patient mean age was $33.7 \pm 12.5$ years with the age range (17-98 years). Most of the patients (56\%) was women and living in urban areas (70.7\%), also the frequency of distribution showed that holder of high school and Diploma certificate were the most (48\%), 22 were uneducated (27.5\%), 54 were holders of postgraduate degree (67.5\%) and 4 were in higher educated (5\%) [18]. Based on results of present study, incidence and prevalence rate of ulcerative colitis in Ardebil city were 2.72 and 19.1 per 100 thousand people respectively [19].

In another investigation in the south of India, 89 (57.7\%) and 68 (43.3\%) of the patients were preferred home-cooked meal and outside food respectively. Out of 204 healthy persons, 67 (32.8\%) of them were preferred home-cooked meal; however, 137 (67.2\%) of them were had outside food. 146 (93\%) patients were non-vegetarian and 11 (7\%) were vegetarians. Evaluation of drinking habits showed that 135 (86\%) patients used municipal water, and 22 (14\%) of the patients used boiled or filtered water in UC sub-population. 157 of UC patients, only 8 (5.1\%) were smokers and among the controls 25 (12.3\%) were smokers. 46 (29.3\%) UC patients consumed alcohol on a regular basis whereas 111 (71.7\%) were non-alcoholic. [20].

In regards to extra-intestinal symptoms, inflammation of joints was $17.5 \%$ among the patients, 
osteopenia and osteoporosis $30.5 \%$ and $17.1 \%$ respectively. Primary sclerosing cholangitis was $0.9 \%$ and vein thrombosis was $1.9 \%, 7.06 \%$ of the population was observed with cutaneous involvement [21].

\section{METHODS AND MATERIALS}

A prospective cross-sectional descriptive study was conducted to determine the epidemiological, clinical presentation and outcome of UC from September 2018 to April 2019. And the study is conducted at General Mosul Hospital, Mosul, Iraq. Which is the main hospital for treatment of gastro intestinal tract (GIT) diseases for many years and that has been giving routine health services for Mosul city and other referral cases from different town of Iraq.

Population for this study includes patients more than 15 years of age who had sustained UC and admitted to hospital for receiving medical care. Data collected from the medical records of 200 patients, hospitalized between September 2018 and end of April 2019. Data included age, sex, residence, educational status, symptoms of UC, environmental factors, risk factors, sensitive to foods, and family history to achieve the objectives of this investigative work, a questionnaire was used to collect data from the UC patient.

A personal interview was held for filling in the questionnaire. All interviews were conducted face to face. The questionnaire was based on the review of literature related to UC. Pre-test was used in $5 \%$ of the sample size before the study to make sure that the data collecting sheet is capable of yielding the required data for the study and some modifications were done according to the results found and to find response from patients. A questionnaire approved by some of specialized physician and health care workers.

Data obtained from this work were tabulated into Microsoft excel sheets and uploaded to SPSS (Statistical Package for Social Sciences) version 22.0 software. Percentage / correlating were used for measurement and analysis. Means used to summarize continuous variables whereas categorical variables to be summarized in form of proportions and frequency tables such as (age, gender, occupation, marital status, educational level, and risk factors). Chisquare $(\chi 2)$ test was used to test for significance of associations between the predictor and outcome variables in the categorical variables to find an outcome related to health issues. Ttest used for comparison two means. $P$-value of $<0.05$ was considered as statistically significant cutoff. The generated data is compiled by frequency tables, charts, and figures. EndNote program and Vancouver style was used for references citation.

\section{RESULTS}

\section{Demographic characteristics of patients}

Out of 200 UC infected patients, 98 (49\%) and 102 (51 \%) were males and females respectively. The mean age was $46.36 \pm 16.57$ years (ranged from 15 to 80 years). More than 45 years old and it considered as the highest proportion of the patients 99 (49.5\%). According to the occupational status, most of frequent patients were not employed 117 (58.5\%), followed by employed 56 (28.0\%), and then military 27 (13.5\%). In addition, the majority of patient was in high school degree and illiterate in educational level 150 (75.0\%) and 33 (16.5\%) respectively and less frequent proportion were in postgraduate level 17 (8.5\%) (Table1).

\section{Severity of UC classifications}

Overall, the patients of the study showed that the more frequency of patients were in severe condition 103 (51.5\%) and lees of them were in mild condition of UC 21 (10.5) (Figure1). 
Extra factors in relation to UC

More antibiotic users likely to be get UC 191 (95.5\%) and the relation was significant at $(p<0.001)$. Also, patients who used corticosteroids they will get to UC at a second proportion $81(40.5 \%)$, it was significant $p=0.01$. Furthermore, there was not any statistical correlation between stress and UC (Table 2).

Table 1. Demographic characteristic of patients Frequency

\begin{tabular}{llcc}
\hline Demographic characteristic & & Number & $\begin{array}{c}\text { Percentage } \\
\text { (\%) }\end{array}$ \\
\hline Sex & Male & 98 & \\
\hline Age group & Female & 102 & 49 \\
\hline & $<30$ & 41 & 20.5 \\
\hline Occupation & $30-45$ & 60 & 30.0 \\
\hline & $>45$ & 99 & 49.5 \\
\hline Educational level & Non employed & 117 & 58.5 \\
\hline & Employed & 56 & 28.0 \\
\hline & Military & 27 & 13.5 \\
\hline Total & Illiterate & 33 & 16.5 \\
\hline & High school degree & 150 & 79.0 \\
\hline & Graduate and postgraduate degree & 17 & 8.5 \\
\hline
\end{tabular}

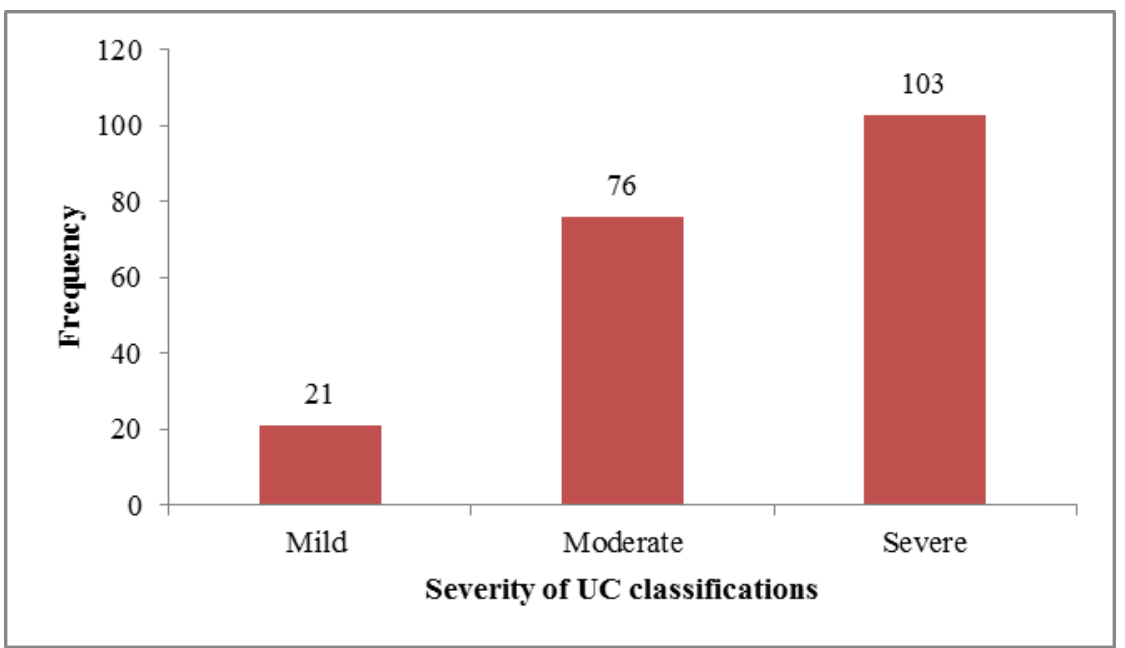

Figure 1. Severity of UC classifications. $n=200$

Table 2. Distribution of extra risk factors in relation to UC. $(\mathrm{n}=200)$

\begin{tabular}{cccc}
\hline Extra factors & No. & $\mathbf{\%}$ & p-value \\
\hline Corticosteroid uses* & 81 & 40.5 & 0.01 \\
\hline Antibiotic uses & 191 & 95.5 & 0.0001 \\
\hline Stress \& anxiety & 68 & 34.5 & 0.5 \\
\hline
\end{tabular}

*Some patient with UC affected by more than one extra factor. 
As shown in figure 2 the severity of UC is increased by continuously using antibiotic and corticosteroids 99 and 48 cases respectively.

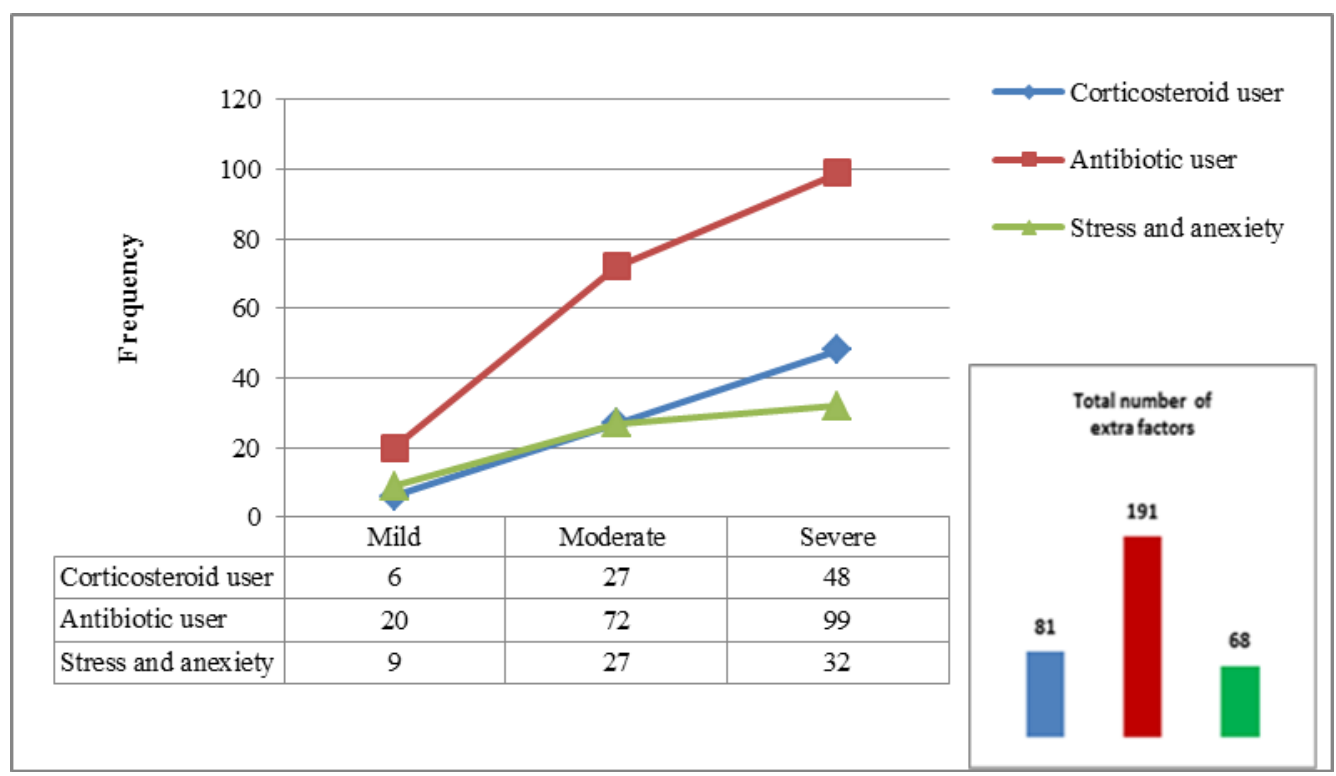

Figure 2. Effect of extra factors on UC severity.

Other risk factors to UC

Overall of the 200 patients, the study showed that 95 (47.5\%) cases had a previous family history of UC, 45 females (22.5\%) were used oral contraceptive pills and 47 (23.5\%) with a history of appendicitis (Table 3).

Table 3. Distributions risks of UC

\begin{tabular}{lcc}
\hline Demographic characteristic & No. & (\%) \\
\hline Family history & 95 & 47.5 \\
\hline Oral contraceptive use $^{\mathbf{a}}$ & 45 & 22.5 \\
\hline Appendicitis & 47 & 23.5 \\
\hline IBS, CD and Celiac disease $^{\mathbf{b}}$ & 13 & 6.5 \\
\hline Total & 200 & 100 \\
\hline
\end{tabular}

a This variable just related to female

${ }^{\mathrm{b}}$ IBS= Irritable bowel disorder, $\mathrm{CD}=$ Crohn's disease

As shown in (Table 4), 42 (44.2\%) cases with family history, 30 (66.7) with oral contraceptive uses, and 23 (48.9\%) with appendicitis are in severe level of UC and there is a significant relation between UC and OCP $(p=0.01)$.

Table 4. Distribution of risk factors in relation to severity of UC. $n=200$

\begin{tabular}{|c|c|c|c|c|c|}
\hline \multirow[b]{2}{*}{ Severity level } & \multicolumn{4}{|c|}{$\begin{array}{c}\text { Type of risks } \\
\text { No. (\%) }\end{array}$} & \multirow[b]{2}{*}{ p-value } \\
\hline & $\begin{array}{l}\text { Family } \\
\text { history }\end{array}$ & $\begin{array}{c}\text { Oral } \\
\text { contraceptive } \\
\text { uses }\end{array}$ & Appendicitis & $\begin{array}{l}\text { IBS, CD and } \\
\text { Celiac disease }\end{array}$ & \\
\hline Mild & $13(13.4)$ & $1(2.2)$ & 7 (14.9) & $0(0.0)$ & \multirow{4}{*}{0.01} \\
\hline Moderate & $40(42.1)$ & $14(31.1)$ & $17(36.2)$ & $5(38.5)$ & \\
\hline Severe & $42(44.2)$ & 30 (66.7) & 23 (48.9) & $8(61.5)$ & \\
\hline Total & 95 & 45 & 47 & 13 & \\
\hline
\end{tabular}

a IBS= Irritable bowel disorder, CD= Crohn's disease 
Gender in relation to UC infection and severity levels

From 102 female patients, 45 (44.1\%) were more frequently under uses of contraceptive pills followed by 37 (36.3\%) with family history of UC, and 16 (15.7\%) with previous history of Appendicitis and these differences were statistically highly significant $\mathrm{p}<0.001$ (Figure 3), additionally from 45 female patients were used oral contraceptive pills 30 (66.7\%) of them are in severe cases of UC followed by 14 (31.1\%) are in moderate cases (Figure 4).

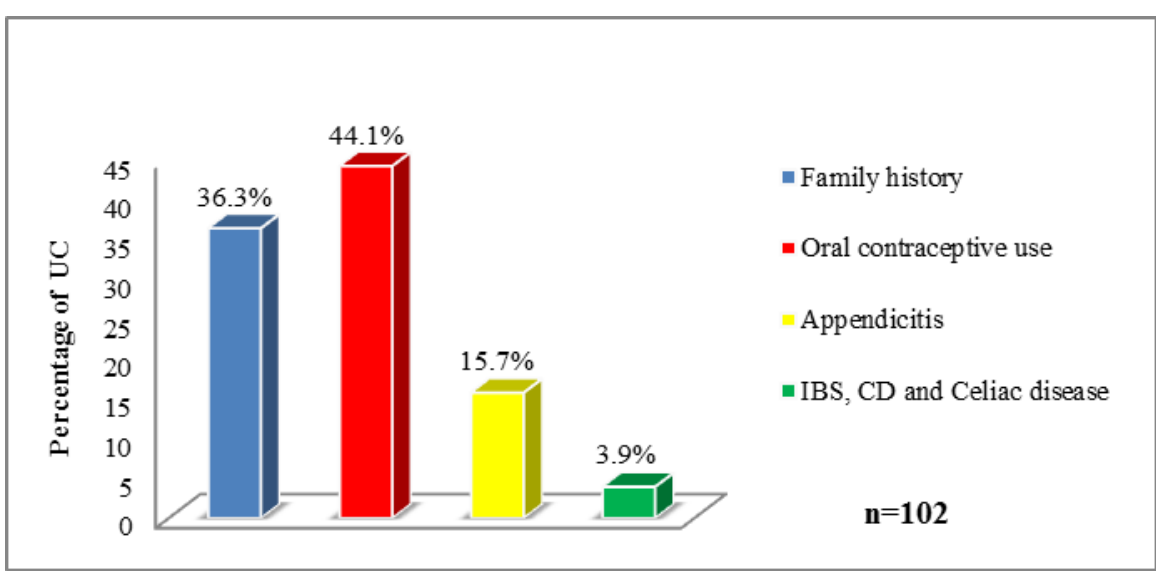

Figure 3. Distribution of risk factors in female gender relations. $p$-value $=0.001$

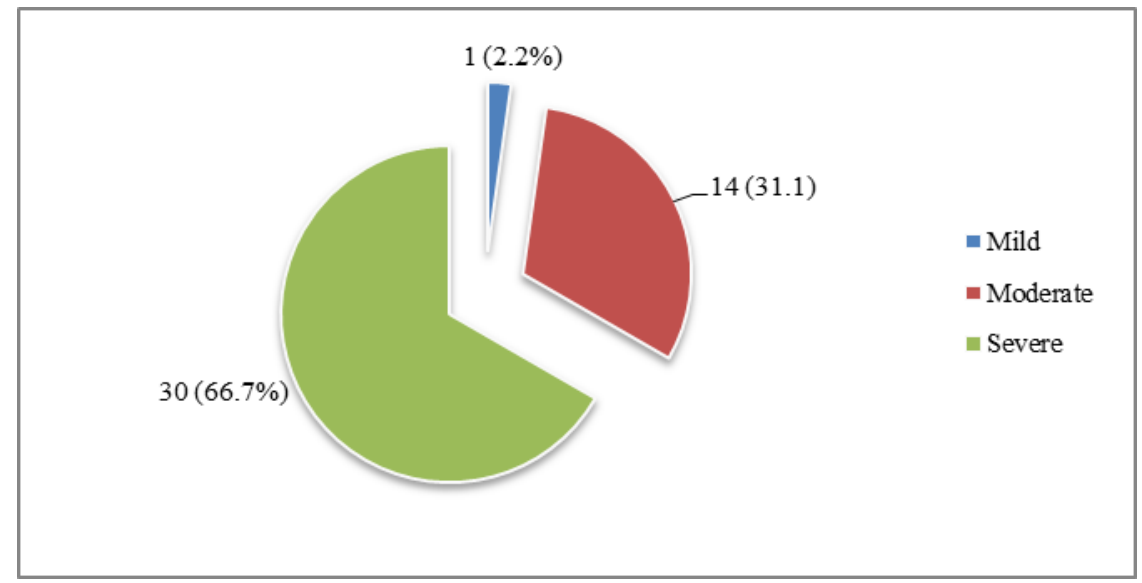

Figure 4. Distributions of severity of UC in female. $n=45$

As shown in (Table 5), a total of 102 females, 60 (58.8\%) were in severe cases of UC followed by moderate 35 (34.3\%), and from 103 severe cases, over all 200 cases, 60 of them were female. These differences statistically significant at $p=0.05$.

Table 5. Distribution of gender in relation to severity of UC.

\begin{tabular}{|c|c|c|c|c|c|}
\hline \multirow[t]{2}{*}{ Gender } & \multicolumn{4}{|c|}{$\begin{array}{c}\text { Severity of UC } \\
\text { No. (\%) } \\
\end{array}$} & \multirow[b]{2}{*}{$p$-value } \\
\hline & Mild & Moderate & Severe & Total & \\
\hline Male & 14 (14.3) & $41(41.8)$ & 43 (43.9) & 98 & \multirow{3}{*}{0.05} \\
\hline Female & $7(6.9)$ & 35 (34.3) & 60 (58.8) & 102 & \\
\hline Total & 21 & 76 & 103 & 200 & \\
\hline
\end{tabular}


Food sensitivity: Table 6 shown that majority of patients previously were sensitive to spices $160(80.0 \%)$ followed by fish and eggs 21 (10.5) vs. 16 (8.0\%) respectively. In addition, from 160 spices sensitive patients $80(50.5 \%)$ of them were in severe cases and $61(38.1 \%)$ were in moderate cases. Statistically these differences are significant at $p=0.04$.

Table 6. Food sensitivity of UC severity.

\begin{tabular}{|c|c|c|c|c|c|c|}
\hline \multirow[t]{2}{*}{ Severity level } & \multicolumn{5}{|c|}{$\begin{array}{l}\text { Type of foods } \\
\text { No. (\%) }\end{array}$} & \multirow[t]{2}{*}{$p$-value } \\
\hline & Spices & Grain & Fish & Milk & Eggs & \\
\hline Mild & $19(11.9)$ & $1(50.0)$ & $1(4.8)$ & $0(0.0)$ & $0(0.0)$ & \multirow{4}{*}{0.04} \\
\hline Moderate & $61(38.1)$ & $1(50.0)$ & $5(23.8)$ & $0(0.0)$ & $9(56.3)$ & \\
\hline Severe & $80(50.0)$ & $0(0.0)$ & $15(71.4)$ & $1(100.0)$ & $7(43.8)$ & \\
\hline Total & $160(80.0)$ & $2(1.0)$ & $21(10.5)$ & $1(0.5)$ & $16(8.0)$ & \\
\hline
\end{tabular}

Age in relation to UC a severity levels and sensitive to foods: The age of the majority cases with severe UC were in those patients older than 30 years as compare with $<30$ years and this difference was statistically significant at $p=0.01$ (Table 7).

Table 7. Distribution of age group in relation to severity of UC.

\begin{tabular}{|c|c|c|c|c|c|}
\hline \multirow[t]{2}{*}{ Age group } & \multicolumn{5}{|c|}{$\begin{array}{l}\text { Type of foods } \\
\text { No. (\%) }\end{array}$} \\
\hline & Mild & Moderate & Severe & Total & $p$-value \\
\hline$<30$ & 7 (33.3) & $21(27.6)$ & $13(4.8)$ & $41(20.5)$ & \multirow{4}{*}{0.01} \\
\hline $30-40$ & 9 (42.9) & $17(22.4)$ & $34(23.8)$ & $60(30.0)$ & \\
\hline$>40$ & $5(23.8)$ & $38(50.0)$ & $56(71.4)$ & $99(49.5)$ & \\
\hline Total & $21(100.0)$ & $76(100.0)$ & $103(10.5)$ & $200(100.0)$ & \\
\hline
\end{tabular}

A total of 200 patients, 160 were sensitive to spices, from those 81 (50.6\%) of were $>40$ yearsold, followed by 30-40 years-old 47 (29.4\%), and <30 years-old 32 (20.0\%), and there was no significant relation $p=0.5$ (Table 8 ).

Table 8. Distribution of previous sensitivity in relation to age. $n=160$

\begin{tabular}{|c|c|c|c|c|c|c|}
\hline \multirow[t]{2}{*}{ Age group } & \multicolumn{5}{|c|}{$\begin{array}{l}\text { Type of foods } \\
\text { No. (\%) }\end{array}$} & \multirow[t]{2}{*}{$p$-value } \\
\hline & Spices & Grain & Fish & Milk & Eggs & \\
\hline$<30$ & $32(20.0)$ & $1(50.0)$ & $5(23.8)$ & $0(0.0)$ & $3(18.8)$ & \multirow{4}{*}{0.5} \\
\hline $30-40$ & $47(29.4)$ & $1(50.0)$ & $5(23.8)$ & $1(100.0)$ & $6(37.5)$ & \\
\hline$>40$ & $81(50.6)$ & $0(0.0)$ & $11(52.4)$ & $0(0.0)$ & 7 (43.7) & \\
\hline Total & 160 & 2 & 21 & 1 & 16 & \\
\hline
\end{tabular}

\section{DISCUSSION}

One of the major health issue in the developing countries is UC, it is the most frequent infection among adult population [22, 23]. In terms of health control, UC is a major problem on the community and especially elderly people are at a high risk for UC [24]. It is known that effective surveillance and early detection of UC in people help in better management of 
patients and reduce emerging other infection related to UC, mortality rate, length of drug administration and associated cost [25]. In the present study, a cross-sectional study was used to determine the epidemiology of UC and factors related to it. Also, to assess the other factors related to severity of UC, and practices to prevent or decrease the occurrence of UC in Mosul city of Iraq. Few studies were conducted about epidemiology and risk factors of UC in Mosul city, Iraq [26, 27], but the current study aims to find out the factors related to UC. The factors of UC were investigated, such as the age, gender, level of UC, foods, and extra factors. Therefore, investigating the epidemiological characteristics and risk factors for UC is essential in our community to provide a better understanding of the problem and to plan preventive services.

In the present study, the mean age was 46.36 years, which is similar to the mean age reported by other studies such as 46.2 years in Baghdad, Iraq [28] and 46.26 years in Morocco [29]. Whereas, studies conducted in Iran [19], in China [30], and in India [31] showed the lowest average of age. Other two studies had a higher mean age 48.4 and 49.3 in south of India [20] and in Turkey [32] respectively than that of the current study.

In the current study, persons with $>40$ years of age shows a high proportion of UC than other age groups (Table1). This finding is nearly consistent to the previous studies which are performed in Erbil, Iraq [28], Saudi Arabia [23] and in England [10]. Nevertheless, many studies around the world have reported that young age (less than 33 years old) are the most frequent groups for UC, such as in Libya [33], United State [34], Sweden [35] and New Zealand [36]. This is probably because these group $(>40)$ in our country most of them having chronic disorder and they use corticosteroids and drugs to treat the problems. Another fact may be due to the body physiological change in our group, which makes them difficult to control.

In the current investigation, there were no statistically significant relationships between age of patients and UC, but severity of UC increased with increasing of age and it observed in the groups more than 45 years of age in comparison with the other group (Table 6). This may also be due to the immunological disorder and hypersensitivity reactions of intestinal walls overtime the age, also psychological problems.

Furthermore, (51.0\%) were more affected to UC than males (49.0\%) (Table1). It is nearly consistent with the other studies such as $60 \%$ in Iran [37], and 67.2\% in Finland [38]. However, other two studies have different reports that males comprise a higher percentage of UC, such as $56.2 \%$ in Turkey [39], and 63.5\% in in Pakistan [40]. The high percentage of female with UC in our study could be due to the increased exposure to activities or hormonal changes and contraceptive using and more antibiotic uses, females are more under stress than males and this is in agreement with the study by Sajadinejad M. [41].

Moreover, there is a significant statistical difference between the gender and severity level of UC ( $p=0.05)$, but females were found to have more severed level than males (Table 5). This could be due to the higher number of admitted female patients in comparison to the female patients or could be due to physiological state of males which is lead to decrease immunological formation of the body and cannot resist especial type of microbe. This finding is in consistence with the previous study which is done by Niv Y et al in Israel [42].

In our study, UC occurs more frequent in non-employed persons (58.5\%) rather than employed person (Table 1). Many of studies around the world have similar results [24, 43, 29]. This finding is in disagreement with a study conducted by Shivananda et al, that showed the UC is more frequent in employed person [44]. Physical demanding occupations with regular working hours for employed person could be factors for decreasing UC. 
Regarding to the extra factors manifestations of UC, we have observed that patients were used or given more antibiotic, they will be more likely to suffer from UC rather than patients with a history of arthritis and they have stress or anxiety, and these relations were statistically significant $(p=0.0001)$ (Table 2$)$. This finding is also similar to the previous studies in Finland and Canada [38, 45].

Regarding to the severity of UC, the study revealed that patients with antibiotic uses for log period were more likely to get severe level of UC (Figure 2 and 3). Thus could be related to the action of drugs which are lead to destroy normal flora inside the intestine and because of the chemical compounds, the wall of the intestine cannot resist those chemical and lead to develop ulcer severely. This finding is nearly in accordance to the previous study by Abbas $\mathrm{J}$ conducted that third degree of UC, antibiotic uses is an important factor and there was significant association found between them [46]. But another study by Xinling et al indicated that there was no association between antibiotic uses and level of UC [30].

This study revealed that the family history is the most risk lead to get UC (47.5\%) (Table 3). This finding is nearly in agreement with the other previous studies; $46.8 \%$ in south Africa [28], 92.6\% in Turkey [27], 88.54\%. For this reason, genetics plays important roles to transfer growth factors for UC, especially among families who are at risk for UC.

In regarding to the association of females with oral contraceptive uses, from a total of 102 female patients, 45 (44.1\%) were more frequently uses of contraceptive pills, we found that most of them were in severe cases of UC, and these association was statistically significant $p=0.001$ (Figure 3). This is outcome confirmed that contraceptive pills are harmful for females and has association with UC and it can be clinically important. A study by Hayder F. et al revealed that there was association between oral contraceptive use and ulcerative colitis incidence in Baghdad, Iraq [27]. However, a study by Hamed Kh. et al conducted that there was no association between oral contraceptive use and ulcerative colitis [47]. This is may be due to the using dose and types of contraceptives pills by the females.

Concerning the food sensitivity, it was found that spice food was the most effective cause for patients to develop UC especially, among late adult persons. A significant relationship was found between UC and age groups $>40 p=0.05$, but other foods are in a less effect to cause UC (Table 8). This is could be due to body sensitivity reactions to those foods or neglecting of persons by repeated uses after onset of sensitivity reactions which lead to negative destroy mechanism actions of intestinal activities and outcome of UC. This finding is in agreement with the result by Xinling $\mathrm{M}$ et al [30]. There are a lot of studies about sensitivity foods found $[28,41,48]$.

Finally, we showed that UC is a common digestive problem in our community and makes a lot of causes to develop and followed complications such as; bleeding, colon surgery or colectomy, and colon cancer. These problems are in cost for the authority and it is difficult to control this problem. In addition, we need to evaluate this issue by conducting more research in the future to find out or determine other causes which lead to UC in Mosul and other Iraqi cities.

Patients who are refractory to corticosteroid are dependent to develop UC. The identification of factors associated with the use of corticosteroid has not been extensively explored, but it has the potential to help predict the patients who are likely to develop severe UC and thus require more intensive therapy. In our study, a positive association was observed between the use of corticosteroid and Antibiotics, including receiving an initial UC diagnosis when under the age of 30, and family history of IBD, extensive colitis, hospitalization, and a history of systemic corticosteroid therapy. 
Another potential mechanism is that in genetically susceptible individuals there is a lack of tolerance to commensal bacteria in the gastrointestinal tract, which leads to activate the gut immune system. Suppression of bacterial flora might lead to down-regulation of the immune system; reduction of inflammation can be achieved with reduction of total bacteria, aerobes, and anaerobes, by antibiotics [49].

\section{CONCLUSION}

This study concluded that the highest risk groups for UC are elderly age for females especially among those families who are living in urban area. The major extra risks for UC were antibiotic uses for long duration and most of the patients with UC are in severe condition. Furthermore, elderly patients are in a high risk for developing severe level of UC. Female patients with UC more likely to get severe level. Usage of oral contraceptive pills is a major cause for UC among females. Spicy food is a greater risk factor for UC and may plays an important role in developing severe cases of UC.

\section{REFERENCE}

[1] D. Joseph, S. Adam, “Ulcerative colitis, Epidemiology, Diagnosis, and Management,” Mayo Clin Proc., 89 (11), pp. 1553-1563, 2014.

[2] H. Matthew, "Human Anatomy,” Webmed, 2017.

[3] SB. Hanauer, "Inflammatory bowel disease,” The New England Journal of Medicine, 334 (13), pp. 841-8, 1996.

[4] Kornbluth A, Sachar DB, "Ulcerative colitis practice guidelines in adults (update): American College of Gastroenterology, Practice Parameters Committee,” The American Journal of Gastroenterology, 99 (7), pp. 1371-85, 2004.

[5] M. Orholm, V. Binder, TI. Sørensen, LP. Rasmussen, KO. Kyvik, “Concordance of inflammatory bowel disease among Danish twins. Results of a nationwide study,” Scandinavian Journal of Gastroenterology, 35 (10), pp. 1075-81,2000

[6] NIDDK, Ulcerative Colitis, September 2014. Archived from the original on 28 July 2016. 2016.

[7] Y. Akiho, A. Azusa, N. Shuich, M. Yuichi, O. Masatoshi, F. Yoshihiro, et al, "Promising biological therapies for ulcerative colitis: A review of the literature," World Journal of Gastrointestinal Pathophysiology. 6 (4), pp. 219-227, 2015.

[8] A. Kornbluth, DB. Sachar, "Ulcerative colitis practice guidelines in adults (update): American College of Gastroenterology, Practice Parameters Committee,” The American Journal of Gastroenterology, 99 (7), pp. 1371-85, 2004.

[9] D. Marc, Ulcerative colitis at medicine, 2018.

[10] DK. Podolsky, “Inflammatory bowel disease,” The New England Journal of Medicine, 347 (6), pp. 41729, 2002.

[11] A. Schmidt, J. Marshall, M. Hayman, "Identification and characterization of the chicken transferrin receptor,” The Biochemical Journal, 232(3), pp. 735-741, 1985.

[12] K. Karlinger, T. Györke, E. Makö, A. Mester, Z. Tarján, “The epidemiology and the pathogenesis of inflammatory bowel disease,” European Journal of Radiology, 35 (3), pp. 154-167, 2000.

[13] S. Shivananda, Lennard- J. Jones, R. Logan, N. Fear, A. Price, L. Carpenter, et al, Incidence of inflammatory bowel disease across Europe: is there a difference between north and south? Results of the European Collaborative Study on Inflammatory Bowel Disease, 2012.

[14] A. Sonnenberg, DJ. McCarty, S.J Jacobsen, "Geographic variation of inflammatory bowel disease within the United States,” Gastroenterology. 100 (1), pp. 143-9, 1991.

[15] S. Wong, S. Ng, "What can we learn from inflammatory bowel disease in developing countries?,” Current Gastroenterology Reports, 15 (3), 2013.

[16] X. Jiang, H. Cui, “An analysis of 10218 ulcerative colitis cases in China,” World Journal of Gastroenterology, 8 (1), pp. 158-161, 2002.

[17] W. Gong, N. Lv, B. Wang, et al., "Risk of ulcerative colitisassociated colorectal cancer in China: a multi-center retrospective study,” Digestive Diseases and Sciences, 57(2), pp. 503- 507, 2012.

[18] G. Koroush, V. Javad, H. Afshin, "Epidemiological and clinical aspects of ulcerative colitis in west of Iran,” SpringerPlus ,5(1588), pp. 3248-4n, 2016.

[19] S. Vahid, A. Firouz, A. Leili, "Epidemiologic study of 80 patients with ulcerative colitis referred to Imam Hospital in Ardabil city during 2004-2011,” International Journal of Research in Medical Sciences, 2(4), pp. 1417-1422, 2014.

[20] G. Sivaram, K. Santosh, B. Avinash, P. Meka, S. Vishnupriya, A. Mohammed, et al., "The epidemiology and prevalence of Ulcerative colitis in the South of India,” Open Journal of Immunology, 2 (4), pp. 144-148, 2012. 
[21] H. Odes, D. Fraser, J. Krawiec, "Ulcerative colitis in the Jewish population of Southern Israel 1961-1985: epidemiological and clinical study,” Gut, 28, pp. 1630-1636, 1987.

[22] NICE, Clinical guideline and quality standard: Ulcerative colitis scope, National Institute for Health and Care Excellence, Ulcerative colitis: management Clinical guideline [CG166], 2011.

[23] AH. Alamin, EA. Ayoola, AS. El-Boshra, MK. Hamaza, V. Gupta, MA. Ahmed, "Ulcerative colitis in Saudi Arabia: a retrospective analysis of 33 cases treated in a regional referral hospital in Gizan,” Saudi J Gastroenterol, 7, pp. 55-58, 2001.

[24] M. Henriksen, J. Jahnsen, I. Lygren, MH. Vatn, B. Moum, “Are there any differences in phenotype or disease course between familial and sporadic cases of inflammatory bowel disease? Results of a population-based follow-up study,” Am J Gastroenterol, 102, pp. 1955-1963, 2007.

[25] EJ. Boyko, TD. Koepsell, DR. Perera, TS. Inui, "Risk of ulcerative colitis among former and current cigarette smokers,” The New England Journal of Medicine, 316 (12), pp. 707-10, 1987.

[26] A. Hatim, S. Noel, "Histochemical and immunohistochemical techniques in ulcerative colitis, Ann. Coll. Med. Mosul, 34(1), pp. 28-34, 2008.

[27] F. Hayder, "Characterization of lymphocyte subsets as a tool of assessment of histological disease activity pattern in ulcerative colitis,” Fac Med Baghdad, 52 (3), 2010.

[28] A. Khalid, "Descriptive study of Extragastrointestinal Manifestations of Ulcerative Colitis and their relation to disease activity in 100 Iraqi patients,” Fac Med Baghdad, 53(1), 2011.

[29] H. Vahedi, S. Merat, S. Momtahen, G. Olfati, AS. Kazzazi, T. Tabrizian, et al., "Epidemiologic characteristics of 500 patients with inflammatory bowel disease in Iran studied from 2004 through 2007,” Arch Iran Med, 12, pp. 454-460, 2009.

[30] M. Xinling, C. Yuke, L. Qianying, L. Hui, and L. Hua, "Food intolerance prevalence in active ulcerative colitis in southwest China,” Asia Pac J Clin Nutr, 25(3), pp. 529-533, 2016.

[31] SN. Khosla, NK. Girdhar, S. Lal, DS. Mishra, "Epidemiology of ulcerative colitis in hospital and select general population of northern India,” J Assoc Physicians India, 34, pp. 405-407, 1986.

[32] A. Fani, "A study on the pattern of prevalence of inflammatory bowel disease and its clinical presentation in Arak,” Rahavard Danesh J Arak Univ Med Sci,18 (5), pp. 28-3, 2002.

[33] A. Ahmaida, S. Al-Shaikhi, "Childhood Inflammatory Bowel Disease in Libya: Epidemiological and Clinical features,” Libyan J Med, 4, pp. 70-74, 2009.

[34] ED. Acheson, MD. Nefzger, "Ulcerative colitis in the United States Army in 1944. Epidemiology: comparisons between patients and controls,” Gastroenterology, 44, pp. 7-19, 1963.

[35] J. Askling, L. Grahnquist, A. Ekbom, Y. Finkel, "Incidence of pediatric Crohn's disease in Stockholm, Sweden,” Lancet, 354 (2), pp. 1179- 80, 1999.

[36] RD. Wigley, BP. MacLaurin, "A study of ulcerative colitis in New Zealand, showing a low incidence in Maoris,” Br Med J, 2, pp. 228-31, 1962.

[37] Z. Mehdi, B. Homayoon, A. Lotfollah, K. Ali, T. Ramin, F. Kiomars, et al, “Ulcerative colitis,” Middle East Journal of Digestive Diseases, 9 (3), pp. 164-169, 2017.

[38] Linden G, "Ulcerative colitis in Finland 11. One year incidence in all hospitals,” Dis Colon Rectum, 14, pp. 264-6, 1971.

[39] C. Güray, P. Emrah, Y. Bülent, C. Hatice, K. Uğur, E. Fatih, "Epidemiologic features of inflammatory bowel disease in Western Blacksea region of Turkey for the last 10 years: retrospective cohort study," Korean J Intern Med, 34, pp. 519-529, 2019.

[40] M. Sajadinejad, K. Asgari, H. Molavi, M. Kalantari, P. Adibi, "Psychological Issues in Inflammatory Bowel Disease: An Overview,” Gastroenterology Research and Practice, 10(1155), pp. 1065-2, 2012.

[41] A. Bret, V. Sunanda, B. Stephen, "Lack of Association between Oral Contraceptive Use and Ulcerative Colitis,” Gastroenterology, 99, pp. 1032-1036, 1990.

[42] Y. Niv, G. Abuksis, GM. Fraser, "Epidemiology of ulcerative colitis in Israel: a survey of Israeli kibbutz settlements,” Am J Gastroenterol, 95, pp. 693-698, 2000.

[43] A. Sonnenberg, DJ. McCarty, SJ. Jacobsen, "Geographic variation of inflammatory bowel disease within the United States.” Gastroenterology, 100, pp. 143-149, 1991.

[44] S. Shivananda, J. Lennard-Jones, R. Logan, N Fear, A. Price, L. Carpenter, et al., "Incidence of inflammatory bowel disease across Europe: is there a difference between north and south? Results of the European Collaborative Study on Inflammatory Bowel Disease (EC-IBD),” Gut, 39, pp. 690-697, 1996.

[45] CN. Bernstein, A. Wajda, LW. Svenson, A. MacKenzie, M. Koehoorn, M. Jackson, et al., "The epidemiology of inflammatory bowel disease in Canada: a population-based study,” Am J Gastroenterol, 101, pp. 15591568, 2006.

[46] J. Abbas, "Detection of Anti-Lactoferrin and Anti-Lysozyme in Ulcerative Colitis Patients," Diyala Journal of Medicine, 21(16), pp. 1, 2019.

[47] K. Hamed, N. Martin, E. Anders, F. Jonas, A. Johan, T. Andrew, et al, "Oral Contraceptive Use and Risk of Ulcerative Colitis Progression: A Nationwide Study,” Am J Gastroenterol, 111(11), pp. 1614-1620, 2016.

[48] MH. Mosli, CE. Parker, SA. Nelson, KA. Baker, JK. MacDonald, GY. Zou, et al., Histologic scoring indices for evaluation of disease activity in ulcerative colitis, Cochrane Database of Systematic Reviews, 2017.

[49] N. Faten, M. Collen, B. Wareen, R. Gary, D. James, “Antibiotic Use and the Risk of Flare of Inflammatory Bowel Disease,” Clinical gastrology and hepatology, 3, pp. 459 -465, 2005. 